\title{
Educación Comparada, Teología y PostRelativismo
}

\author{
García Ruiz, María José \\ UNED, Madrid, España \\ mjgarcia@edu.uned.es
}

\section{Resumen}

Los procesos de Globalización y Postmodernismo han determinado la necesidad de operar un reajuste del corpus epistemológico de la disciplina comparativa de la educación necesario para integrar las exigencias gnoseológicas de dichos discursos en nuestro saber. Adicionalmente a ello, la resolución de las vulnerabilidades científicas de la Educación Comparada, y el logro de una fase postrelativista en la construcción del discurso de nuestra ciencia, requiere del concurso del trabajo interdisciplinar en la elaboración de dicho discurso. Particularmente imperioso se revela en el abordaje de los retos epistemológicos aludidos el acometimiento de un trabajo interdisciplinar con las ciencias teleológicas de la educación que cimienten y asienten en bases sólidas la elaboración y articulación de una disciplina comparativa fecunda y estable, más allá de los cambios naturales que conllevan los ciclos históricos sucesivos.

\section{Abstract}

The phenomena of Globalization and Postmodernism have determined the need to overtake a readjustment of the epistemological corpus of the comparative discipline in Education, necessary to integrate the demands of such discourses in our academic field. Additionally, the resolution of the scientific vulnerabilities of Comparative Education, and the achievement of a postrelativistic phase in the construction of the discourse of our discipline, demand the competition of an interdisciplinary work in the construction of such discourse. Particularly overriding in the approach of the epistemological challenges mentioned, is the commitment of an interdisciplinary work with teleological sciences of education, that allow the foundation and settlement in solid basis of a fertile and stable comparative discipline, beyond the natural changes of successive historical cycles.

Palabras clave: Globalización, Postmodernidad, Educación Comparada, epistemología, interdisciplinariedad, Teología.

Keywords: Comparative education, epistemology, interdisciplinariety, theology.

\section{VULNERABILIDAD Y FORTALEZA DE LA EDUCACIÓN COMPARADA}

El carácter internacional y transfronterizo del proceso de la Globalización conduce inexorablemente a la potenciación y legitimación de disciplinas como la Educación Comparada. En este sentido, al parecer de algunos académicos de relieve «la Educación Comparada nunca ha tenido tanto éxito (...)» (Carney, 2010, p. 125). En la misma línea, autores como Cowen y Kazamias prodigan la gran fecundidad de esta disciplina en estos primeros años del siglo XXI en términos de producción científica y organización de congresos y redes internacionales (Cowen \& Kazamias, 2009, pp. 3-4). No obstante, estos autores matizan y apuntalan su diagnóstico introduciendo un cierto escepticismo en sus manifestaciones en relación a la salud real de nuestra disciplina: «la Educación Comparada nunca ha tenido menos que decir» (Carney, 2010, p. 125); «Las estructuras superficiales de la Educación Comparada -sus revistas, sus departamentos, sus sociedades profesionales- parecen gozar de una excelente salud. Por debajo de la superficie, no obstante, hay confusiones en relación a lo que de hecho es la Educación Comparada o lo que ella podría ser» (Cowen, 2009, p. 964). 
Los académicos comparatistas de la educación nos hallamos en un momento de reajuste del corpus epistemológico y metodológico de la disciplina necesario para integrar las exigencias gnoseológicas de los discursos postmodernos en nuestro saber. Con vistas a que este proceso sea operado con las máximas garantías de fecundidad y éxito, la comunidad comparatista de la educación debemos acometerlo desde el reconocimiento de los puntos vulnerables de nuestra ciencia, y de los elementos -también- de extraordinaria fortaleza que permiten la vertebración de nuestra disciplina en sólidas bases futuras.

Las dificultades epistemológicas de la Educación Comparada son reconocidas por la gran mayoría de académicos comparatistas de los diversos entornos geográficos. Así, Rappleye (2014, p. 93) afirma que «(...) la disciplina está (...) de forma incesante en búsqueda de sí misma». Por su parte, Manzón (2014, p. 127) se pregunta: "¿por qué no hay una forma universal de Educación Comparada?». La pluralidad (algo caótica, podemos decir) del ámbito de la Educación Comparada ha sido resumida por académicos como Cowen en la afirmación de que «existen muchas educaciones comparadas» (2009, p. 4). En su emblemática obra de Fundamentos de la epistemología de la Educación Comparada, el catedrático español García Garrido también se hace eco de las «discusiones y muchos más desacuerdos sobre su objeto» (1996, p. 113) que tradicionalmente han caracterizado a la epistemología de esta ciencia. García Garrido enumera hasta seis posturas existentes defendidas por los diversos académicos comparatistas en relación al objeto científico de la Educación Comparada (1996, pp. 9296). Así, si bien la disciplina de la Educación Comparada se revela un ámbito científico de gran tradición y solera que se remonta a la Antigüedad Grecorromana, en estos primeros años del siglo XXI esta ciencia sigue revelando una extraordinaria pluralidad, heterogeneidad, hibridación, diversidad y eclecticismo que han determinado la gran dificultad experimentada por los académicos consagrados a la misma en articular de manera consensuada elementos epistemológicos básicos como, muy particularmente, el objeto de estudio de la misma. Podemos afirmar sin ningún género de dudas, que esta heterodoxia y disenso en relación al elemento más nuclear y sensible de un campo científico -su objeto de estudio- constituye una de las mayores vulnerabilidades, quizá la mayor, que aquejan al desarrollo unánime y coordinado del corpus epistemológico comparativo en educación.

Un segundo elemento de vulnerabilidad en nuestro ámbito disciplinar lo constituye la cuestión metodológica. Hace unas décadas, el desarrollo de la disciplina comparativa de la educación en líneas de Modernidad reveló un cierto consenso metodológico en torno al cual se articuló el trabajo de los comparatistas: «(...) el acuerdo sobre la existencia y aplicabilidad a la educación del método comparativo ha sido una constante - juna de las pocas! - entre los cultivadores de nuestra disciplina, de Jullien a nuestros días» (García Garrido, 1996, p. 114). No obstante, este mismo experto comparatista admite, tras ello, la existencia de enfoques diversos en la metodología comparada (ie. descripción, explicación, aplicación, valoración) y, a la postre, la «validez científica de una pluralidad de enfoques metodológicos» y la necesidad de «evitar la tentación del monopolio metodológico» (ibídem, pp. 115121); además de reconocer la existencia de métodos y técnicas auxiliares que incluyen la contribución de la reflexión filosófica, de la metodología histórica y de las aportaciones de las ciencias sociales (ibídem, pp. 136-166).

El aspecto metodológico de las investigaciones comparativas constituye una de las partes más sensibles y relevantes de los estudios de nuestro ámbito. El editorial del mes de noviembre de 2017 de la norteamericana Comparative Education Review, CER, reivindica el «rigor y solidez metodológicas de los manuscritos» que se envíen a esta revista, tanto si los estudios comparativos se vertebran en líneas cuantitativas como cualitativas. El equipo editorial de la CER comunica que, en lo que atañe al plano metodológico, las decisiones editoriales se adoptan en base a la «fortaleza de este análisis» (Editorial, CER, noviembre 2017, vol. 61, número 4).

En la solventación de las vulnerabilidades de nuestra disciplina, el trabajo interdisciplinar no sólo se revela imperativo y crucial, sino que constituye una de las principales fortalezas de los estudios comparados acreditados. Cowen revela el hecho de que la revitalización intelectual de la Educación Comparada se ha producido "desde fuera» de la disciplina y, muy especialmente, procede del ámbito de la Sociología y la Historia (Cowen, 2009, pp. 1.279-1.280). Este académico apunta al ascenso del trabajo teórico comparativo problematizado gracias a las aportaciones del marxismo y sus variaciones, además de a los escritos en relación al colonialismo y al análisis de los sistemas mundiales. El Catedrático Emérito García Garrido también alude en su obra al hecho de que «la Educación Comparada es un ámbito sustancialmente interdisciplinario» (1996, p. 138), esbozando que "es deseable que el comparatista tenga una buena formación previa en al menos un campo de especialización (Historia, Ciencia Política, Sociología, Economía, etc.), además de en Pedagogía (1996, p. 139). La interdisci- 
plinariedad constituye, pues, la principal fortaleza de nuestra disciplina, y sólo si en la construcción epistemológica de la misma contamos con los aportes gnoseológicos y metodológicos de otras ciencias, la Educación Comparada podrá fortalecerse y salir robustecida de los embistes globalizadores y postmodernos con los que se enfrenta en estos años del siglo XXI. Adicionalmente, por su carácter de ciencia de rango analítico sintético, la Educación Comparada no debe sólo relacionarse con las ciencias analíticas de índole antropológica y metodológica de la educación -que son con las que tradicionalmente ha tenido más relación (ie. Sociología, Política)- sino también muy especialmente con las analítico sintéticas (ie. Historia), las sintéticas (ie. Pedagogía General) y, en estos complejos años de comienzos del siglo XXI, muy primordialmente con las disciplinas teleológicas (ie. Filosofía y Teología). En este tiempo de globalización y modernidad tardía, la Educación Comparada sólo logrará cimentar y estabilizar su objeto de estudio, y sólo se verá capacitada para dar cumplida y eficaz respuesta a sus finalidades teóricas y aplicadas si desarrolla su epistemología de forma conjunta muy especialmente con las ciencias teleológicas. Retomaremos esta reflexión en líneas posteriores.

\section{MODERNIDAD, POSTMODERNIDAD Y POSTRELATIVISMO}

Precisamente, la grave y prolongada carencia de un trabajo interdisciplinar en Educación Comparada es la responsable de la «ausencia de rol de la comunidad de comparatistas de la educación en la discusión postmoderna» (Rust, 1991, p. 614). Según el comparatista Val D. Rust, «la idea postmoderna ha existido en la ciencia social y la literatura estética desde la década de 1950 (ibídem, p. 610). El historiador Perry Anderson, de la Universidad de California (UCLA), en su obra Los orígenes de la posmodernidad, remonta más atrás en el tiempo el origen de este fenómeno. Así, Anderson afirma que la idea de postmodernismo emergió primero en el intermundo hispano en los años treinta del siglo XX, una generación antes de su aparición en Inglaterra y los EE.UU. (Anderson, 2000, p. 8). La aparición de este término en el mundo anglófono no se produjo sino hasta veinte años más tarde, en un contexto muy distinto y como categoría histórica más que estética (ibídem, p. 9).

La Postmodernidad, también denominada posthumanismo, posthistoricismo (Kunitz, 1955) o Post-Occidente (Olson, 1987), no alcanzó difusión más amplia hasta los años setenta. La primera obra filosófica que adoptó la noción fue La condition postmoderne de Jean-François Lyotard, publicada en 1979 en Paris. Según Anderson, el rasgo definitorio de la condición postmoderna (2000, p. 31-32) es la pérdida de credibilidad de las metanarrativas modernas. En el ámbito de la Educación Comparada, uno de los primeros trabajos comparatistas que integran el postmodernismo en la epistemología de esta disciplina fue el de Val D. Rust, en el año 1991, con su artículo Postmodernism and Its Comparative Education Implications, publicado en la norteamericana Comparative Education Review.

Podemos afirmar que, si la modernidad se vincula a ideas de tradición continuada, Cristianismo, Europa, racionalismo, universalismo, normativismo, tradición, moralidad, historia y virtudes, la postmodernidad se asocia a ideas de ruptura, cultura de lo nuevo, movilidad, aceleración de la historia, discontinuidad, nuevo valor atribuido a lo transitorio, lo esquivo y lo efímero (Habermas, 1988, p. 89), rebelión contra todo lo que es normativo, contra la tradición, posthistoricismo (García Ruiz, 2011) y, muy especialmente, a un parámetro muy característico de la epistemología postmoderna, que constituye uno de los rasgos más presentes y generalizados en la cultura de la modernidad tardía, que ha sido muy contestado por la gran mayoría de los académicos, y cuyo análisis detenido debemos necesariamente acometer para dar respuesta a las inquietudes epistemológicas que suscita en la construcción de conocimiento científico y comparativo. Este parámetro es el relativismo.

El rasgo del relativismo es un atributo universalmente reconocido como signo y símbolo del estado epistemológico de la postmodernidad. Anderson (2000, p. 33) afirma que el relativismo «pasa por ser la marca distintiva de la postmodernidad». El profesor Cowen, en sus escritos en el International Handbook of Comparative Education de 2009 alude al "problema relativista» y se pregunta, como interrogante e inquietud epistemológica primordial actual: «¿dónde están los límites del relativismo?». Académicos y teólogos como el Papa Emérito Benedicto XVI se refieren a la «Dictadura del relativismo» como signo del estado epistemológico característico de estos años del siglo XXI (Sayés, 2012, p. 9).

El fenómeno del relativismo consiste y surge a partir de la crisis y negación de las metanarrativas universales. Desde el prisma de la construcción del conocimiento científico, hablamos de relativismo epistemológico. En los argumentos de los comparatistas de la educación que han abordado «el 
problema relativista» (Cowen, 2009, p. 961), como el británico Cowen, es, no obstante, el relativismo ético el que con mayor presencia y fuerza inquieta e impacta en los actuales planteamientos epistemológicos (frente a otros tipos de relativismo como el cultural, el individual o el sociológico). La inquietud de Cowen más objetivamente explicitada radica en el conocimiento de la entidad e identidad del momento concreto y de los criterios específicos que deben presidir la emisión de juicios (mayormente ausentes en los escritos de los comparatistas, afirma él) «condenadores de modelos educativos (...) como la presión extrema impuesta a los alumnos por los sistemas de exámenes en Japón, Hong Kong o Corea del Sur» (ibídem, p. 962).

El relativismo es, de hecho, «el rasgo de la Postmodernidad más enérgicamente rechazado por un gran número de académicos» (García Ruiz, 2012, p. 48). Tampoco todos los académicos admiten la relegación y el rechazo en estos tiempos de modernidad tardía de atributos característicos de la Modernidad de gran valía como, muy especialmente, la tradición y la verdad. En su obra Relativismo y tolerancia, Poole Derquí avanza la crítica de que «todo relativismo que pretenda ser razonado implica una contradicción consigo mismo: si ningún criterio puede ser verdadero, el juicio de que toda verdad es relativa tampoco puede tener carácter de validez absoluta, lo que destruye, con sus propias armas, al relativismo» (2016, pp. 8-9).

Desde la reflexión académica personal en relación al statu quo epistemológico de la Educación Comparada, considero que el trabajo científico de nuestra disciplina ha estado durante su desarrollo en los siglos XIX y XX (y también en el actual siglo XXI), fundamental y exclusivamente centrada en los procesos educativos (ie. el funcionamiento de los sistemas educativos; la entidad de las políticas y las reformas educativas, etc.). Esos procesos son cambiantes por naturaleza y por evolución histórica y, por ello, una ciencia cimentada de forma exclusiva en los mismos, no acaba de encontrar su arraigo doctrinal (más allá de que una disciplina siempre tiene que estar abierta a la evolución con las nuevas etapas históricas). La Educación Comparada ha descuidado a lo largo de su historia su atención gnoseológica a los actores del proceso educativo (ie. muy especialmente la concepción de persona humana sujeto de la acción educativa comparativa), y a la finalidad de dicho proceso (ie. notablemente, la idea de la sociedad mundial pretendida y hacia la que se tiende). La concepción de la persona humana no varía ni está sujeta a las crisis de los tiempos, y la finalidad última y más esencial de la sociedad mundial (en términos de paz mundial y felicidad, al estilo de un Proyecto de una ética mundial, como la propuesta por el teólogo Hans Küng) tampoco. Sólo desde una Educación Comparada de cuño también filosófico y teológico (y no meramente histórico, sociológico y político) tendrán respuesta inquietudes como las mostradas por Cowen relativas a los criterios que deben presidir la emisión de juicios -hasta ahora «mayormente ausentes en los escritos de los comparatistas»- (Cowen, 2009, p. 962).

Es mi convicción personal y académica que el logro de una cimentación epistemológica sólida de la disciplina comparativa pasa por la articulación y vertebración de una firme y cristiana idea de persona y sociedad (actores), y de los fines culturales y sociales europeos y mundiales (finalidad), en cuya articulación se requiere el concurso de las directrices y presupuestos ontológicos procedentes de las ciencias teleológicas: la Filosofía y, muy especialmente, la Teología. En estos momentos de relativismo y de negación de las metanarrativas universales, sólo determinados presupuestos de la ciencia teológica pueden establecerse como componentes de una epistemología postrelativista y superar la tan mentada posverdad como aseveración que no se basa en hechos objetivos, sino en las emociones, creencias o deseos.

Podemos afirmar que este aparente consenso y triunfo del secularismo reinante dista, en el fondo, de atestiguar todo el cuadro de la situación espiritual de nuestro tiempo. Reputados comparatistas como el profesor Cowen, en su emblemático International Handbook of Comparative Education, IHCE, al hablar de la construcción de la identidad en tiempos moderno-tardíos, alude al hecho de que «en la alteración de la naturaleza de los entornos educativos en la modernidad tardía, la cuestión de las culturas educativas y la identidad pedagógica tiende a desvincularse de nociones como ciudadanía, y a devenir más y más poderosamente vinculada a la economía o la religión» (Cowen \& Kazamias, 2009, p. 6. La cursiva es mía). De hecho, los comparatistas Cowen y Kazamías, en su IHCE dedican una sección entera de esta obra a la temática religiosa. De igual modo, la conferencia presidencial del Dr. David P. Baker en la norteamericana Comparative and International Education Society, CIES, en el año 2013, reivindicó más investigación educativa comparada e internacional a la relación entre educación y religión: "Quizá un fenómeno más descuidado y prometedor de investigación para la Educación Comparada e Internacional es la entidad de la religión y la espiritualidad en la sociedad escolarizada» (Baker, 2014, p. 16). Las siguientes palabras tienen muchas implicaciones para los com- 
paratistas: «Esto revela un gran potencial para la investigación de la Educación Comparada e Internacional, que ha estado virtualmente muda en la materia. Hasta la fecha, toda la investigación ha sido realizada por científicos sociales interesados en la religión, no particularmente en educación. Esto demanda un estudio comparado más sistemático. Y es un tema futuro central para la investigación en Educación Comparada e Internacional» (ibídem, p. 18). La Educación Comparada como ciencia debe apuntar, en su doble finalidad teórico-práctica, y en su condición de ciencia analítico-sintética, a dar cumplida respuesta a esta dimensión espiritual, y a apuntar a elevados horizontes espirituales y axiológicos para la sociedad mundial actual. Este y no otro es el mejor legado que esta disciplina puede dejar a los futuros ciudadanos mundiales. También esta finalidad axiológica conlleva y supone una cimentación sólida de la epistemología de la disciplina comparativa, pues dichos horizontes teleológicos se revelan de estabilidad permanente, aun cuando la sociedad humana evolucione y cambie. Estas reflexiones nos conducen al siguiente -y último- epígrafe de este estudio.

\section{TEOLOGÍA Y EDUCACIÓN COMPARADA}

Al comienzo del artículo hemos analizado la situación fragmentada y estéril de la epistemología comparada en estos años del siglo XXI. Es mi hipótesis que, en la revitalización de nuestro campo de estudio, la Educación Comparada debe asumir su rol central en relación a la definición de la naturaleza y atributos de la persona humana íntegramente considerada objeto de la educación en su trabajo comparado, y también en lo que atañe a la conformación de las finalidades históricas, sociales y espirituales de las culturas mundiales a que dichas personas pertenecen y cuyo logro se ansía. Podríamos establecer como objeto de estudio de la Educación Comparada en los actuales tiempos postmodernos, el siguiente: «El logro, a través de la educación y los sistemas, políticas y reformas educativas mundiales, de personas y sociedades libres, comprometidas y desarrolladas en todas sus dimensiones, y de culturas y civilizaciones solidarias e inclusivas, a través del método comparado y el consejo de las ciencias teológicas del saber». Este autor lanza un mensaje de esperanza, optimismo y firmeza en el cuerpo de doctrina extenso y completo, elaborado durante el pontificado de San Juan Pablo II: el Catecismo. «Nunca la Iglesia, en ninguna época, ha contado con un cuerpo de doctrina tan amplio y tan perfecto, se trate de temas dogmáticos, bíblicos, morales, etc.». "El Catecismo es «una auténtica catedral de doctrina que durará mucho tiempo como ley de orientación» (ibídem, $p$. 34). Al decir de Sayés: "Gracias a Dios, a pesar de la crisis actual, la lglesia sabe lo que cree» (ibídem, p. 36). De este vasto cuerpo doctrinal, cabe extraer algunas de las finalidades últimas para las sociedades y culturas mundiales (ie. atención a la dimensión transcendente; carácter comunitario de la vocación humana, virtudes, deseo de felicidad y vocación a la bienaventuranza, acción libre y responsable, justicia social, moralidad de los actos humanos, etc.).

El concepto de persona, tan usado por las ciencias del espíritu, tiene una profunda raíz en la teología cristiana occidental. Esta raíz cristiana, reflexionada, madurada y articulada desde la época patrística, medieval, renacentista y contemporánea, ha configurado no sólo el concepto sino, además, una reflexión en torno al valor y dignidad del hombre. En el pensamiento de los grandes teólogos de los siglos XX y XXI, la persona humana tiene un gran significado en su dimensión teologal-relacional (Buriticá, 2014, pp. 467-468); como persona abierta y en relación con lo trascendente. Pedro Abelló alude a las trece notas del concepto de persona, cuya integración y consideración en toda actividad educativa deberían contemplarse: 1) naturaleza espiritual, 2) libertad, 3) centralidad, 4) unicidad/inaprensibilidad, 5) singularidad, 6) condición de sujeto y soporte del ser, 7) dinamismo/autosuperación, 8) virtualidad/potencialidad, 9) sinergismo, 10) universalidad, 11) relacionalidad, 12) autonomía, 13) naturaleza sacrificial.

\section{DISCUSIÓN Y CONCLUSIONES}

Los académicos comparatistas nos enfrentamos, en esta segunda década del siglo XXI, a la construcción epistemológica de la ciencia comparativa de la educación desde el contexto cultural y filosófico de la postmodernidad y sus planteamientos de crisis del universalismo, complejidad, impredictibilidad, y pérdida de las legitimaciones tradicionales. La resolución de la crisis epistemológica de nuestra disciplina de la Educación Comparada, y de sus vulnerabilidades gnoseológicas, y la sanción de una 
fase científica postrelativista, requiere del trabajo interdisciplinar con las ciencias teleológicas que proporcionen unos elementos científicos a nivel de actores y finalidades del proceso educativo comparado, que cimienten y orienten definitiva y sólidamente la disciplina y la capaciten para proseguir su desarrollo teórico de forma consolidada y firme.

\section{REFERENCIAS BIBLIOGRÁFICAS}

Abelló, P. Sobre el concepto de persona. En http://es.catholic.net/op/articulos/54939/cat/403/sobre-el-concepto-de-persona.html. Anderson, P. (2000). Los orígenes de la posmodernidad. Madrid: Akal.

Aullón de Haro, P. (2018). La cuestión universitaria y las ciencias humanas en tiempos de globalización. Metodologías Humanísticas en la Era Digital, vol 1, 15-43.

Baker, D. P. (2014). Minds, Politics and Gods in the Schooled Society: Consequences of the Education Revolution. Comparative Education Review, 58, 1, 6-23.

Buriticá Zuluaga, D. A. (2014). El concepto de persona humana en la tradición cristiana y su progresión hasta el personalismo. Cuestiones Teológicas, vol. 41, n 96, pp. 467-493.

Carney, S. (2010). Reading the Global: Comparative Education at the End of an Era. En M. A. Larsen (Ed.), New Thinking in Comparative Education (125-142). Rotterdam: Sense Publishers.

CER Editorial Team (2017). On Methodology in Comparative and International Education. Comparative Education Review, vol $61, n^{\circ} 4,669-674$.

Cowen, R. (2009). Editorial Introduction: New Thinking. En R. Cowen and A. Kazamias (Eds.), International Handbook of Comparative Education (961-964). Dordrecht: Springer.

Cowen, R. and Kazamias, A. (2009). Joint Editorial Introduction. En R. Cowen and A. Kazamias (Eds.), International Handbook of Comparative Education (3-6). Dordrecht: Springer.

Discurso del Papa Juan Pablo II en el Acto Europeo en Santiago de Compostela, martes 9 de noviembre de 1982.

García Garrido, J. L. (1996). Fundamentos de la Educación Comparada. Madrid: Dykinson. García Ruiz, M. J. (2011). Impacto de la Globalización en la universidad europea del siglo. XXI. Revista de Educación, 356, pp. 509-529.

García Ruiz, M. J. (2012). Impacto de la Globalización y el Postmodernismo en la epistemología de la Educación Comparada. Revista Española de educación Comparada, vol 20, 41-80.

Habermas, J. (1988). Modernidad versus Postmodernidad. En J. Picó (Ed.), Modernidad y Postmodernidad. Madrid: Alianza Editorial.

Küng, H. (2006). Proyecto de una Ética Mundial. Madrid: Editorial Trotta. $7^{a}$ ed. Kunitz, S. J. (Ed.) (1955). Twentieth Century Authors - First Supplement. Nueva York.

Manzón, M. (2014). Cambio de forma de la Educación Comparada: hacia una historia comparada de la disciplina. En M. Larsen (Ed.), Pensamiento Innovador en Educación Comparada. Homenaje a Robert Cowen (127-151). Madrid: UNED.

Olson, C. (1966). Projective Verse. En R. Creeley, (Ed), Selected Writings. Nueva York. Poole Derqui, D. (2016). Relativismo y Tolerancia. Madrid: Digital Reasons.

Rappleye, J. (2014). Brújulas, mapas y espejos: reubicando la epistemología de la transferencia. Reorientando el cosmos comparativo. En M. Larsen (Ed.), Pensamiento Innovador en Educación Comparada. Homenaje a Robert Cowen (93-123). Madrid: UNED. Rust, V. D. (1991). Postmodernism and its Comparative Education Implications. Comparative Education Review, 35, 4, 610-626.

Sayés, J. A. (2012). Teología y relativismo. Análisis de una crisis de fe. Madrid: BAC. Schriewer, J. (2000) (Ed). Discourse Formation in Comparative Education. Frankfurt am Main: Peter Lang.

Sotelo Martínez, I. (2003). La invención de Europa: la realidad histórico-cultural de Europa. En AA.VV., La formación de europeos. Actas del Simposio de Barcelona. Madrid: Academia Europea de Ciencias y Artes. 